\title{
Continuation Therapy Epoch
}

National Cancer Institute

\section{Source}

National Cancer Institute. Continuation Therapy Epoch. NCI Thesaurus. Code C123452.

A period in a clinical study during which subjects receive continuation therapy. This therapy is usually different from the therapy given during the induction phase and administered over a longer period of time. 